\title{
Urine neutrophil gelatinase-associated lipocalin to predict renal response after induction therapy in active lupus nephritis
}

\author{
Bancha Satirapoj ${ }^{* *}$, Chagriya Kitiyakara², Asada Leelahavanichkul ${ }^{3}$, Yingyos Avihingsanon ${ }^{3}$ \\ and Ouppatham Supasyndh ${ }^{1}$
}

\begin{abstract}
Background: Tubulointerstitial injury is important to predict the progression of lupus nephritis (LN). Urine neutrophil gelatinase-associated lipocalin (NGAL) has been reported to detect worsening LN disease activity. Thus, urine NGAL may predict renal outcomes among lupus patients.

Methods: We conducted a prospective multi-center study among active LN patients with biopsy-proven. All patients provided urine samples for NGAL measurement by ELISA collected from all patients at baseline and at 6-month followup after induction therapy.

Results: In all, 68 active LN patients were enrolled (mean age $31.7 \pm 10.0$ years, median UPCR $4.8 \mathrm{~g} / \mathrm{g}$ creatinine level with interquartile range (IQR) 2.5 to 6.9 and mean estimated glomerular filtration rate (GFR) $89.6 \pm 33.7 \mathrm{~mL} / \mathrm{min} / 1.73 \mathrm{~m}^{2}$ ). At baseline measurement, median urinary NGAL in complete response, partial response and nonresponse groups was 10.86 (IQR; 6.16, 22.4), 19.91 (IQR; 9.05, 41.91) and $65.5(I \mathrm{IQR} ; 18.3,103) \mathrm{ng} / \mathrm{mL}$, respectively $(p=0.006)$. Urinary $\mathrm{NGAL}(\mathrm{ng} / \mathrm{mL})$ correlated positively with proteinuria and blood pressure, and correlated negatively with serum complement C3 level and estimated GFR. Based on ROC analysis, urinary NGAL (AUC; $0.724,95 \% \mathrm{Cl} 0.491-0.957$ ) outperformed conventional biomarkers (serum creatinine, urine protein, and GFR) in differentiating complete and partial response groups from the nonresponse group. The urine NGAL cut-off value in the ROC curve, $28.08 \mathrm{ng} / \mathrm{mL}$, discriminated nonresponse with 72.7\% sensitivity and $68.4 \%$ specificity.
\end{abstract}

Conclusion: Urine NGAL at baseline performed better than conventional markers in predicting a clinical response to treatment of active LN except serum complement C3 level. It may have the potential to predict poor response after induction therapy.

Keywords: Neutrophil gelatinase-associated lipocalin (NGAL), systemic lupus erythematosus (SLE), lupus nephritis (LN), ROC curve

\section{Background}

Renal involvement among Asian patients with systemic lupus erythematosus (SLE) in the form of active nephritis is associated with a significant burden of morbidity and mortality [1]. Early detection and prompt treatment with immunosuppressive agents can dramatically change the course of renal disease and improve long-term

\footnotetext{
* Correspondence: satirapoj@yahoo.com

${ }^{1}$ Division of Nephrology, Department of Medicine, Phramongkutklao Hospital and College of Medicine, 315 Rachavitee Road, Phyathai, Bangkok 10400, Thailand

Full list of author information is available at the end of the article
}

survival [2, 3]. Current conventional biomarkers have not been very successful in predicting renal histology and patient outcomes. Noninvasive methods should be investigated to assess the renal response with standard treatment among these patients.

Tubulointerstitial damage is important to predict the progression of glomerular diseases and lupus nephritis (LN) [4]. Neutrophil gelatinase-associated lipocalin (NGAL) is a $25-\mathrm{kd}$ protein secreted by leukocytes and tubular epithelial cells under differing conditions with stress and inflammation [5]. Initially, NGAL has been reported in tubular cells and urine in an experimental 
model of ischemic and nephrotoxic renal injury [6]. Several clinical studies have also demonstrated that concentrations in urine of NGAL represented very sensitive and highly predictive biomarkers for progressive tubular and glomerular injury [7-10]. Moreover, in a study of SLE patients, an increase in urinary levels of NGAL correlated with renal disease activity [11]. Urinary NGAL biomarkers are much easier obtained and might represent a sensitive measurement of kidney injury and local inflammatory activity among LN patients. For these reasons, this study was designed to measure urine NGAL among LN patients and we hypothesized that the levels of urinary NGAL would significantly correlate with the severity of renal disease activity and investigated its predictive performance in renal response after induction therapy.

\section{Methods}

\section{Population}

All SLE patients with biopsy-proven LN class III, IV or $\mathrm{V}$ were recruited in the study. Patients fulfilled at least four of the American College of Rheumatology 1982 revised criteria to diagnose SLE. We excluded all patients with drug induced lupus, active malignancies, overlapping syndromes, urinary tract infection, active systemic infection and history of renal transplantation from this study. All patients received standard induction therapy with IV cyclophosphamide or mycophenolate. After 6 months of induction therapy, patients were divided in three groups based on renal response to treatment. These groups of patients with complete response, partial response and nonresponse were defined by return of serum creatinine to previous baseline plus a decline in urinary protein to urinary creatinine ratio (UPCR) to $<500 \mathrm{mg} / \mathrm{g}$, stabilization or improved serum creatinine level plus a $\geq 50 \%$ decrease in UPCR and sustained 25\% increase in serum creatinine level or a $<50 \%$ decrease in UPCR, respectively. Informed consent was obtained from all patients who participated in this study.

\section{Clinical and laboratory measurement}

Relevant demographic data of all patients were obtained, as was information on medication regimens. All patients underwent routine laboratory assessments at their outpatient clinic visit. Blood samples were obtained to determine complete blood cell count, serum creatinine level, serum chemistry and serum complement (C3), antinuclear antibodies (ANA) and anti-dsDNA antibody. Estimated glomerular filtration rate (GFR) was assessed using the Chronic Kidney Disease Epidemiology Collaboration (CKD-EPI) equation [12]. A complete urinalysis was performed and the UPCR was obtained.
Disease activity was assessed using the SLE Disease Activity Index (SLEDAI) that "weighted" the index of disease activity in nine organ systems [13]. Renal involvement was assessed with a renal SLEDAI score of 4, corresponding to the presence of any one of the following concerning urine analysis: hematuria, proteinuria, pyuria or urinary red cell casts. The renal histologic features were evaluated by a renal pathologist. Activity index scores were calculated from the summing of individual scores. The range of activity index score was 0 to 24 with higher scores representing higher activity [14]. Chronicity index scores were calculated from the summation of individual scores. The range of chronicity index score was 0 to 12 with higher scores representing higher chronicity [14]. A percentage of each parameter of activity index and chronicity index was calculated by standard method.

\section{NGAL enzyme-linked immunosorbent assay}

Urine samples were collected at baseline and after complete induction therapy. Samples were centrifuged at $4000 \mathrm{rpm}$ for $10 \mathrm{~min}$ to remove particular impurities, then stored frozen at $-80^{\circ} \mathrm{C}$ until assayed. Urinary NGAL level was measured by a commercially available sandwich enzyme-linked immunosorbent assay (ELISA) kit from R\&D Systems Inc., USA with coefficients of variation for variation less than $10 \%$, for intra-assay and inter-assay variation. The enzymatic reactions were quantified in an automatic microplate photometer. All measurements were made in triplicate and blinded manner. Urinary NGAL excretions were reported as the amount of urinary NGAL in nanograms per milliliter $(\mathrm{ng} / \mathrm{mL})$ and urinary NGAL in nanograms per milligram (ng/mg) of urine creatinine to correct for differences in NGAL due to urine dilution.

\section{Statistical analysis}

Statistical analysis was performed using SPSS statistical software, version 16.0 (SPSS, Chicago, IL). Data were given as mean \pm SD or median with interquartile range (IQR). Comparisons of categorical variables were conducted using Chi-square testing. For nonparametric data, the differences between groups were analyzed by the Mann-Whitney U and Kruskal-Wallis tests. Spearman correlation coefficients was used as appropriate to test correlations between urine NGAL and other variables. Receiver operating characteristic (ROC) analysis was used to calculate the area under the curve (AUC) with associated 95\% confidence interval (CI) for urine NGAL and the usual standard biomarkers used to predict renal response and to find the best cut-off values to identify the renal response after induction therapy. $P$ values less than 0.05 were considered significant. 


\section{Results}

\section{Patient characteristics}

A total of 68 patients were included in this study, 17 with complete response, 40 with partial response and the other 11 with nonresponse after induction therapy. Most patients were female $(97.1 \%)$ with a mean age of $31.7 \pm 10.0$ years. Mean body mass index was within normal range. About $20 \%$ of patients had systemic symptoms from SLE. Most of patients were classified as LN class IV defined as proliferative lesion involving 50\% or more of glomeruli. Coclassification with class $\mathrm{V}$ was found among 14 patients $(20.6 \%)$. Median score of activity index and chronicity index was 8 (IQR 6-11.5) and 2 (IQR 0-3), respectively. Characteristics of the patients are summarized in Table 1.

\section{Conventional biomarkers related to renal response}

Laboratory biomarker results in the three groups of patients are shown in Table 2. As expected, active LN patients with complete renal response had significantly lower baseline levels of urine protein and renal chronic index, and had significantly higher levels of C3 complements. There was no difference in estimated GFR between the three groups $(P=0.467)$. No significant differences were found regarding age, sex, duration of disease, renal SLEDAI and renal activity pathology score between the three groups of patients. Moreover, there were no significant differences in the baseline conventional biomarkers including urine NGAL between cyclophosphamide and mycophenolate treatment.

\section{Baseline urine NGAL with renal activity and renal response}

Among active LN patients, baseline urinary NGAL levels were significantly lower among those with complete response (median $10.86 \mathrm{ng} / \mathrm{mL}$, IQR 6.16 to 22.4) than among those with partial response (median $19.91 \mathrm{ng} / \mathrm{mL}$, IQR 9.05 to 41.91), and nonresponse (median $65.5 \mathrm{ng} / \mathrm{mL}$, IQR 18.3 to 103$)(P=0.006)$ (Fig. 1a). However, no significant differences were observed in urine NGAL to urine creatinine ratio among the three groups of patients (Fig. 1b).

To determine whether urinary NGAL was associated with renal activity, we performed a correlation between various baseline renal parameters and level of urine NGAL. Level of urine NGAL $(\mathrm{ng} / \mathrm{mL})$ correlated with rising of UPCR $(r=0.280, p=0.021)$, higher systolic blood pressure $(r=0.360, p=0.003)$, higher diastolic blood pressure $(r=0.359, p=0.003)$, lower estimated GFR $(r=-0.262, p=0.031)$, and low complement C3 $(r=-0.389, p=0.005)$. No correlation was observed between age, positive anti-DNA antibody, SLEDAI score, serum creatinine, and level of urine NGAL $(\mathrm{ng} / \mathrm{mL})$. However, level of urine NGAL (ng/mg creatinine)
Table 1 Clinical characteristics

\begin{tabular}{|c|c|c|}
\hline Variables & $\begin{array}{l}\mathrm{N}(\%) \text { or } \\
\text { mean } \pm \mathrm{SD}\end{array}$ & $\begin{array}{l}\text { Median } \\
\text { with IQR }\end{array}$ \\
\hline Female (N, \%) & $66(97.1 \%)$ & \\
\hline Age (years) & $31.7 \pm 10.0$ & $32(23,38)$ \\
\hline Body weight (kg) & $54.7 \pm 14.9$ & $50.9(45.9,62)$ \\
\hline Body mass index & $20.1 \pm 3.9$ & \\
\hline Duration of SLE (years) & $6.3 \pm 6.3$ & $4(2,8.5)$ \\
\hline Systolic blood pressure (mmHg) & $126.7 \pm 24.3$ & $128(119,138.5)$ \\
\hline Diastolic blood pressure $(\mathrm{mmHg})$ & $79.4 \pm 19.2$ & $78.5(70,92)$ \\
\hline \multicolumn{3}{|l|}{ Systemic organ involvements ( $\mathrm{N}, \%)$} \\
\hline Arthritis & $14(20.6 \%)$ & \\
\hline Cutaneous lupus & $14(20.6 \%)$ & \\
\hline Hematologic involvement & $8(11.8 \%)$ & \\
\hline Serositis & $4(5.9 \%)$ & \\
\hline Neurological involvement & $1(1.5 \%)$ & \\
\hline Baseline SLEDAI score & $10.8 \pm 3.3$ & $10(8,12)$ \\
\hline Baseline Renal SLEDAI score & $7.0 \pm 2.9$ & $8(4,8)$ \\
\hline \multicolumn{3}{|l|}{ ISN/RPS class (N, \%) } \\
\hline Class III & $5(7.4 \%)$ & \\
\hline Class IV & $49(72.1 \%)$ & \\
\hline Class III + V & $4(5.9 \%)$ & \\
\hline Class IV + V & $10(14.7 \%)$ & \\
\hline Renal activity index & $8.5 \pm 2.9$ & $8(6,11.5)$ \\
\hline Renal chronicity index & $1.9 \pm 1.7$ & $2(0,3)$ \\
\hline \multicolumn{3}{|l|}{ Immunosuppressive agents ( $\mathrm{N}, \%)$} \\
\hline $\begin{array}{l}\text { Induction with high } \\
\text { cyclophosphamide }\end{array}$ & $37(62.7 \%)$ & \\
\hline Induction with mycophenolate & $22(37.3 \%)$ & \\
\hline $\begin{array}{l}\text { Mean dose of mycophenolate } \\
\text { (mg/day) }\end{array}$ & $29.6 \pm 17.1$ & $30(20,35)$ \\
\hline Prednisolone & $67(98.5 \%)$ & \\
\hline Hydroxychloroquine & $32(47.1 \%)$ & \\
\hline \multicolumn{3}{|c|}{ Anti-hypertensive and lipid lowering agents ( $N, \%$ ) } \\
\hline RAAS blockers & $51(75 \%)$ & \\
\hline Calcium channel blockers & $10(14.7 \%)$ & \\
\hline Diuretics & $28(41.2 \%)$ & \\
\hline Statins & $43(63.2 \%)$ & \\
\hline \multicolumn{3}{|l|}{ Laboratory data } \\
\hline Positive ANA (\%) & $67(98.5 \%)$ & \\
\hline Positive anti-dsDNA (\%) & $57(83.8 \%)$ & \\
\hline $\begin{array}{l}\text { Low complement component } \\
3 \text { (C3) (\%) }\end{array}$ & $31(60.8 \%)$ & \\
\hline $\begin{array}{l}\text { Serum complement component } \\
\text { C3 levels (g/L) }\end{array}$ & $1.2 \pm 1.8$ & $0.7(0.4,1.1)$ \\
\hline Hematocrit (\%) & $26.5 \pm 11.2$ & $30(13.7,34.6)$ \\
\hline Serum albumin (g/dL) & $2.7 \pm 0.9$ & $3(2,3.2)$ \\
\hline Serum creatinine (mg/dL) & $0.9 \pm 0.5$ & $0.8(0.7,1.1)$ \\
\hline Estimated GFR (mL/min/1.73 m²) & $89.6 \pm 33.7$ & $89.4(63.7,116.8)$ \\
\hline UPCR (g/g creatinine) & $5.9 \pm 4.8$ & $4.8(2.5,6.9)$ \\
\hline \multicolumn{3}{|c|}{$\begin{array}{l}\text { Abbreviations ANA antinuclear antibody, Anti-dsDNA anti-double-stranded DNA antibody, } \\
\text { ISN/RPS International Society of Nephrology/Renal Pathology Society, GFR glomerular filtration } \\
\text { rate, RAAS renin angiotensin aldosterone system, SLEDAI systemic lupus erythematosus } \\
\text { disease activity index, UPCR urine protein creatinine ratio } \\
\text { Values for categorical variables are given as number (percentage); values for } \\
\text { continuous variables, as mean } \pm \text { standard deviation or median [interquartile range] }\end{array}$} \\
\hline
\end{tabular}


Table 2 Baseline conventional renal biomarkers with renal response after induction therapy

\begin{tabular}{|c|c|c|c|c|}
\hline & $\begin{array}{l}\text { Complete response } \\
(n=17)\end{array}$ & $\begin{array}{l}\text { Partial response } \\
(n=40)\end{array}$ & $\begin{array}{l}\text { Non-response } \\
(n=11)\end{array}$ & $\begin{array}{l}P \\
\text { value }\end{array}$ \\
\hline Renal activity index & $7(5,11)$ & $9(6,12)$ & $8(6,10)$ & 0.760 \\
\hline Renal chronicity index & $0(0,3)^{a, b}$ & $2(0,3)^{c}$ & $3(3,4)^{a, b, c}$ & 0.008 \\
\hline SLEDAl score & $12(10,14)^{a}$ & $10(8,12)^{a}$ & $12(8,16)$ & 0.018 \\
\hline Renal SLEDAI score & $8(4,8)$ & $4(4,8)$ & $8(8,12)$ & 0.077 \\
\hline Positive Anti-dsDNA (\%) & $17(100 \%)$ & 39 (97.5\%) & $11(100 \%)$ & 0.705 \\
\hline Serum complement C3 levels ( $\mathrm{g} / \mathrm{L}$ ) & $0.4(0.3,0.6)^{a, b}$ & $0.8(0.5,1)^{\mathrm{a}, \mathrm{c}}$ & $1.3(0.9,1.4)^{a, b, c}$ & 0.001 \\
\hline Hematocrit (\%) & $29(13.1,33.6)$ & $30.3(11.9,35.8)$ & $32.9(14.9,36)$ & 0.568 \\
\hline Serum albumin (g/dL) & $2.9(2.3,3.3)$ & $3(2,3)$ & $3(3,3.2)$ & 0.573 \\
\hline Serum creatinine (mg/dL) & $0.8(0.6,0.9)$ & $0.9(0.7,1.2)$ & $0.7(0.7,1.2)$ & 0.553 \\
\hline Estimated GFR $\left(\mathrm{mL} / \mathrm{min} / 1.73 \mathrm{~m}^{2}\right)$ & $98.5(85.3,118.5)$ & $84.2(59.2,111.7)$ & $96.2(53.7,120.2)$ & 0.467 \\
\hline UPCR (g/g creatinine) & $3.1(2,4.5)^{\mathrm{a}}$ & $5.5(3.9,8.6)^{a}$ & $4.6(2.1,6.9)$ & 0.011 \\
\hline
\end{tabular}

Abbreviations Anti-dsDNA anti-double-stranded DNA antibody, GFR glomerular filtration rate, RAAS; renin angiotensin aldosterone system, SLEDAl systemic lupus erythematosus disease activity index, UPCR urine protein creatinine ratio

Values for categorical variables are given as median [interquartile range]

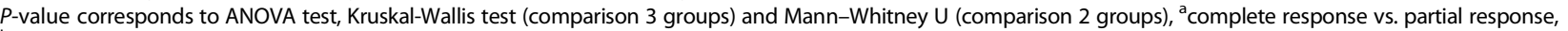

${ }^{\mathrm{b}}$ complete response vs. nonresponse and ${ }^{\mathrm{C}}$ partial response vs. nonresponse

Define term of complete response is return of serum creatinine to previous baseline, plus a decline in the UPCR to $<500 \mathrm{mg} / \mathrm{g}$

Define term of partial response is stabilization $( \pm 25 \%)$, or improvement of $\mathrm{SCr}$, but not to normal, plus a $\geq 50 \%$ decrease in UPCR. If there was nephrotic-range

proteinuria, improvement requires a $\geq 50 \%$ reduction in UPCR, and a UPCR $<3000 \mathrm{mg} / \mathrm{g}$

Define term of non-response is a sustained $25 \%$ increase in serum creatinine or a $<50 \%$ decrease in UPCR

correlated with rising of serum creatinine $(r=0.344$, $p=0.004)$ and lower estimated GFR $(r=-0.270$, $p=0.026)$ (Table 3).

\section{Performance of urine NGAL in predicting renal response} Regarding ROC analysis, urinary NGAL (ng/mL) (AUC; 0.770, 95\%CI 0.604-0.937) outperformed conventional biomarkers (serum creatinine, urine protein, and GFR) in differentiating complete and partial response groups from nonresponse group. The AUC for serum C3 complement was 0.821 (95\% CI: $0.686-0.956: P=0.004)$ that was higher than those for urine NGAL. However, the AUCs for urine NGAL (ng/mg creatinine), UPCR, estimated GFR and serum creatinine were $0.483(P=0.877), 0.512(P=0.917)$, $0.465(P=0.756)$, and $0.465(P=0.756)$, respectively. These were lower than those for urine NGAL (ng/mL) (Fig. 2).

Using the ROC curve data and respective specificity and sensitivity values, optimal thresholds for urine NGAL and complete or partial response after induction therapy were selected. The optimal urine NGAL concentration was $28.08 \mathrm{ng} / \mathrm{mL}$, discriminating nonresponse with $72.7 \%$ sensitivity and $68.4 \%$ specificity (Table 4 ).
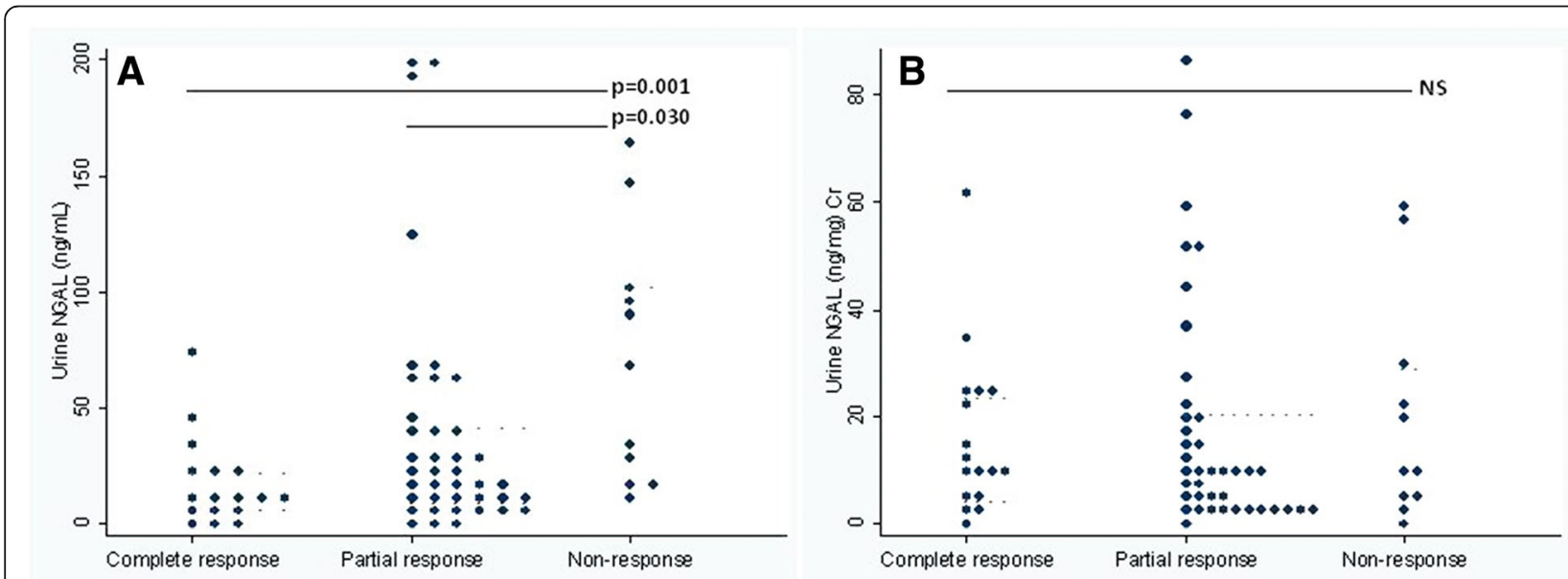

Fig. 1 Baseline urinary NGAL among LN patients with renal response after induction therapy a Baseline urinary NGAL (ng/mL) among LN patients with renal response after induction therapy and $\mathbf{b}$ Baseline urinary NGAL to creatinine ratio (ng/mg $\mathrm{Cr}$ ) among LN patients with renal response after induction therapy 
Table 3 Correlation of urine NGAL with other parameters at baseline in active lupus nephritis

\begin{tabular}{|c|c|c|c|c|}
\hline & Urine NGAL (ng/ & & Urine NGAL (ng & \\
\hline & Spearman's rho & $p$-value & Spearman's rho & $p$-value \\
\hline Age (years) & 0.089 & 0.473 & 0.001 & 0.992 \\
\hline ACEls or ARBS & -0.018 & 0.883 & 0.007 & 0.955 \\
\hline Diuretics & -0.059 & 0.635 & -0.116 & 0.344 \\
\hline Systolic blood pressure $(\mathrm{mmHg})$ & 0.360 & 0.003 & 0.198 & 0.105 \\
\hline Diastolic blood pressure (mmHg) & 0.359 & 0.003 & 0.045 & 0.715 \\
\hline SLEDAI score & -0.079 & 0.523 & 0.034 & 0.780 \\
\hline Renal SLEDAI score & 0.069 & 0.576 & 0.086 & 0.485 \\
\hline Positive anti-dsDNA antibody & 0.040 & 0.743 & -0.171 & 0.163 \\
\hline Serum complement C3 levels ( $g / L$ ) & 0.273 & 0.053 & 0.038 & 0.793 \\
\hline Low complement C3 & -0.389 & 0.005 & -0.130 & 0.365 \\
\hline Serum creatinine $(\mathrm{mg} / \mathrm{dL})$ & 0.231 & 0.058 & 0.344 & 0.004 \\
\hline UPCI (g/g creatinine) & 0.280 & 0.021 & -0.014 & 0.910 \\
\hline Estimated GFR $\left(\mathrm{mL} / \mathrm{min} / 1.73 \mathrm{~m}^{2}\right)$ & -0.262 & 0.031 & -0.270 & 0.026 \\
\hline
\end{tabular}

Abbreviations ACEl, angiotensin converting enzyme inhibitor, Anti-dsDNA anti-double-stranded DNA antibody, ARBs, angiotensin receptor blockers, GFR glomerular filtration rate, RAAS renin angiotensin aldosterone system, SLEDAI systemic lupus erythematosus disease activity index, UPCR urine protein creatinine ratio
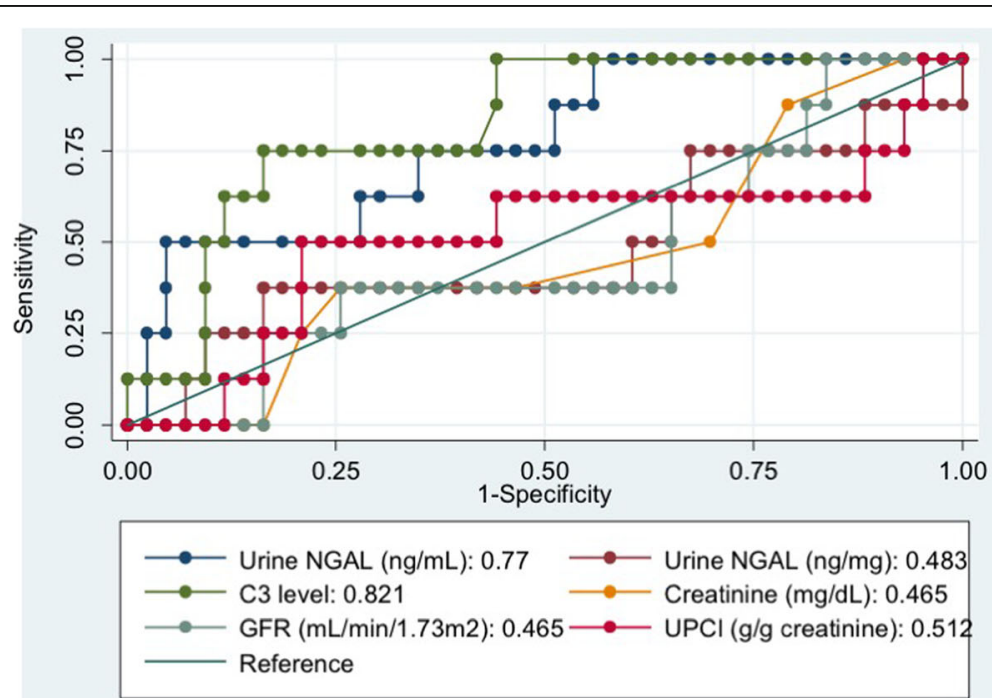

\begin{tabular}{|l|c|c|c|c|}
\hline \multicolumn{1}{|c|}{ Variables } & $\begin{array}{c}\text { Area Under } \\
\text { the Curve }\end{array}$ & \multicolumn{2}{c|}{$\begin{array}{c}95 \% \text { Confidence } \\
\text { Interval }\end{array}$} & P-value \\
\hline Serum C3 complement level & 0.821 & 0.686 & 0.956 & 0.004 \\
\hline Urine NGAL (ng/mL) & 0.770 & 0.604 & 0.937 & 0.016 \\
\hline Urine NGAL (ng/mg Cr) & 0.483 & 0.234 & 0.731 & 0.877 \\
\hline UPCR (g/g creatinine) & 0.512 & 0.257 & 0.766 & 0.917 \\
\hline GFR (mL/min/1.73 $\left.\mathrm{m}^{2}\right)$ & 0.465 & 0.252 & 0.679 & 0.756 \\
\hline Serum creatinine (mg/dL) & 0.465 & 0.253 & 0.677 & 0.756 \\
\hline $\begin{array}{l}\text { Urine NGAL (ng/mL) and serum C3 } \\
\text { complement level }\end{array}$ & 0.779 & 0.617 & 0.941 & 0.013 \\
\hline $\begin{array}{l}\text { Urine NGAL (ng/mL) and serum } \\
\text { creatinine }\end{array}$ & 0.782 & 0.617 & 0.946 & 0.012 \\
\hline $\begin{array}{l}\text { Urine NGAL (ng/mL), serum C3 } \\
\text { complement level and serum } \\
\text { creatinine }\end{array}$ & & & & \\
\hline
\end{tabular}

Fig. 2 Graph ROC curves showing Area under the Curve (AUC) of urine NGAL to predict renal response after induction therapy. Abbreviations: GFR; Glomerular filtration rate, UPCR; Urine protein creatinine ratio, UNGAL; urine neutrophil gelatinase associated lipocalin 
Table 4 Cut-off levels for urine NGAL in predicting renal response after induction therapy

\begin{tabular}{|c|c|c|c|c|c|}
\hline $\begin{array}{l}\text { Cut off: } \\
\text { Urine NGAL } \\
\text { (ng/mL) }\end{array}$ & Sensitivity & Specificity & PPV & NPV & Accuracy \\
\hline 18.01 & $81.8 \%$ & $50.9 \%$ & $24.3 \%$ & $93.5 \%$ & $55.9 \%$ \\
\hline 18.45 & $72.7 \%$ & $50.9 \%$ & $22.2 \%$ & $90.6 \%$ & $54.4 \%$ \\
\hline 18.79 & $72.7 \%$ & $52.6 \%$ & $22.9 \%$ & $90.9 \%$ & $55.9 \%$ \\
\hline 19.91 & $72.7 \%$ & $54.4 \%$ & $23.5 \%$ & $91.2 \%$ & $57.4 \%$ \\
\hline 21.40 & $72.7 \%$ & $56.1 \%$ & $24.2 \%$ & $91.4 \%$ & $58.8 \%$ \\
\hline 22.18 & $72.7 \%$ & $57.9 \%$ & $25.0 \%$ & $91.7 \%$ & $60.3 \%$ \\
\hline 22.51 & $72.7 \%$ & $59.6 \%$ & $25.8 \%$ & $91.9 \%$ & $61.8 \%$ \\
\hline 23.01 & $72.7 \%$ & $61.4 \%$ & $26.7 \%$ & $92.1 \%$ & $63.2 \%$ \\
\hline 23.45 & $72.7 \%$ & $63.2 \%$ & $27.6 \%$ & $92.3 \%$ & $64.7 \%$ \\
\hline 24.98 & $72.7 \%$ & $64.9 \%$ & $28.6 \%$ & $92.5 \%$ & $66.2 \%$ \\
\hline 27.24 & $72.7 \%$ & $66.7 \%$ & $29.6 \%$ & $92.7 \%$ & $67.6 \%$ \\
\hline 28.08 & $72.7 \%$ & $68.4 \%$ & $30.8 \%$ & $92.9 \%$ & $69.1 \%$ \\
\hline 28.32 & $63.6 \%$ & $68.4 \%$ & $28.0 \%$ & $90.7 \%$ & $67.6 \%$ \\
\hline 30.16 & $63.6 \%$ & $71.9 \%$ & $30.4 \%$ & $91.1 \%$ & $70.6 \%$ \\
\hline 34.12 & $63.6 \%$ & $73.7 \%$ & $31.8 \%$ & $91.3 \%$ & $72.1 \%$ \\
\hline 36.79 & $54.5 \%$ & $73.7 \%$ & $28.6 \%$ & $89.4 \%$ & $70.6 \%$ \\
\hline 38.92 & $54.5 \%$ & $77.2 \%$ & $31.6 \%$ & $89.8 \%$ & $73.5 \%$ \\
\hline 41.91 & $54.5 \%$ & $78.9 \%$ & $33.3 \%$ & $90.0 \%$ & $75.0 \%$ \\
\hline 44.24 & $54.5 \%$ & $80.7 \%$ & $35.3 \%$ & $90.2 \%$ & $76.5 \%$ \\
\hline 54.21 & $54.5 \%$ & $82.5 \%$ & $37.5 \%$ & $90.4 \%$ & $77.9 \%$ \\
\hline 63.73 & $54.5 \%$ & $86.0 \%$ & $42.9 \%$ & $90.7 \%$ & $80.9 \%$ \\
\hline 64.90 & $54.5 \%$ & $87.7 \%$ & $46.2 \%$ & $90.9 \%$ & $82.4 \%$ \\
\hline 65.45 & $54.5 \%$ & $89.5 \%$ & $50.0 \%$ & $91.1 \%$ & $83.8 \%$ \\
\hline 66.64 & $45.5 \%$ & $89.5 \%$ & $45.5 \%$ & $89.5 \%$ & $82.4 \%$ \\
\hline 70.72 & $45.5 \%$ & $91.2 \%$ & $50.0 \%$ & $89.7 \%$ & $83.8 \%$ \\
\hline 82.96 & $45.5 \%$ & $93.0 \%$ & $55.6 \%$ & $89.8 \%$ & $85.3 \%$ \\
\hline
\end{tabular}

\section{Discussion}

Renal involvement that is the main determinant of poor prognosis of SLE supports the need to identify biomarkers to assess the risk of disease development and to follow-up patients with established disease. In recent years, different studies have underlined the crucial role played by the renal tubule in the genesis of progressive acute and chronic glomerulonephritis and its evolution to end stage renal disease [15]. Importantly, in lupus with renal pathology, renal function correlated better with the degree of tubule-interstitial lesions than that of the glomerular lesion. Novel biomarkers of the processes that induce these tubulointerstitial changes may ultimately prove to be better predictors of disease progression and long-term prognosis than our current markers. [4] Findings from the present study clearly indicate that urinary NGAL levels and serum C3 complement might be novel risk markers of $\mathrm{LN}$ response to induction therapy beyond the information provided by serum creatinine and other conventional risk factors.

NGAL is a member of the lipocalin family of proteins which is highly expressed in activated leukocytes and other types of cells including tubular epithelial cells with injury [16]. In the initial study, NGAL enhanced excretion in the urine and predicted the future appearance of acute kidney injury in a variety of acute clinical settings $[7,8]$. Recent evidence found that NGAL probably induced antibody mediated nephritis by caspase 3 activated apoptosis and up-regulated inflammatory gene expression [17] and also modulated the levels of autoantibodies in animal models of lupus [18]. For all these reasons, NGAL may become one of the most promising next-generation biomarkers in immune mediated nephritis including LN patients. At present, several studies have reported that high levels of urinary NGAL was detected among SLE individuals in the presence of nephritis and urine NGAL may be a predictor of LN disease activity and flares and predicts worsening of LN disease activity [19-21]. In our study, urine NGAL from LN patients related to conventional biomarkers of LN disease activity including urine protein and serum $\mathrm{C} 3 \mathrm{com}$ plement. Our finding also showed that active LN with nonresponse to induction therapy had the highest baseline urine NGAL levels, thus providing further evidence for urine NGAL as a predictor for treatment outcome.

Initial data suggested that increased urine NGAL in chronic glomerulonephritis was due to massive protein loss that may saturate the megalin cubilin transporters on the renal tubular cells, leading to reduced NGAL reabsorption [16]. In addition, NGAL mRNA and protein was rapidly induced in the proximal and distal renal tubules in the experimental model of progressive kidney injury [22]. One study among SLE patients also confirmed a significant positive correlation between the urine NGAL level and 24-h urinary protein [23]. Our results were consistent with previous studies [10, 24], revealing a highly significant positive correlation between urine protein and urine NGAL level among all LN patients.

Our study showed no associations between urine NGAL levels with renal function and renal SLEDAI scores for evaluating renal lupus activity. Our findings contrast those reported by other authors suggesting that high urine NGAL reflected the renal components of the SLEDAI score and worsening renal function [25-27]. This discrepancy can be explained by the fact that these authors had compared urine NGAL levels among SLE patients with and without nephritis. However, all patients in our study had biopsy-proven LN without severe renal impairment and limited variation of serum creatinine and renal SLEDAI scores among complete, partial and nonresponse groups. 
In our study, the AUCs for serum C3 complement $(0.802)$ and urine NGAL $(\mathrm{ng} / \mathrm{mL})(0.769)$ were greater than those for other parameters (proteinuria, serum creatinine and estimated GFR). The sensitivity and specificity in predicting renal response were $75 \%$ and 66.7\%, respectively. Previous studies among SLE patients have also reported the strong association of urine NGAL [19-21] and serum C3 complement in active LN [28, 29], but data from the Aspreva Lupus Management Study (ALMS) study indicated that only baseline C4 complement level, and early normalization of complement but not C3 complement independently predicted renal response to therapy at 6 months [30]. Proteinuria and estimated GFR are commonly used in clinical practice to evaluate LN activity and response to treatment. Unexpectedly, no significant difference in baseline of serum creatinine and GFR was observed among SLE with and without renal response and we did not find these parameters in predicting $\mathrm{LN}$ response to induction therapy. This finding can be explained by the fact that most patients in our study presented active renal disease among SLE patients with limited variation in levels of proteinuria and renal function. Moreover, previous studies used differing reference standards to define renal response or active renal disease activity, and the incongruous reference standards could have led to variance in the outcomes of the present study. In contrast to our study, previous data demonstrated that elevations in serum creatinine and UPCR may reflect ongoing late phase of renal inflammation and were found to be unreliable in predicting the severity of the renal pathology and treatment responses among patients with biopsy-proven LN [31].

Novel urine biomarkers of kidney injury are being studied, and much interest has been shown in the appropriateness and validity of applying urine creatinine normalization. The assumption is that urine creatinine excretion is constant across and within individuals. In our study, the urine NGAL to creatinine ratio was not reflected in the renal response and performed poorly in predicting renal response, but was not detected with urine NGAL $(\mathrm{ng} / \mathrm{mL})$. The findings can be explained by the fact that urine creatinine excretion in acute kidney disease is a dynamic process affected by glomerular iltration and tubular secretion, such as urine creatinine decreases in proportion to the magnitude of the decrease in GFR, hence abruptly increasing normalized biomarker levels [32]. Nevertheless, normalized levels of a urine biomarker such as NGAL reflecting tubular injury can be influenced by dynamic changes in the urine creatinine excretion rate [33]. Therefore, creatinine normalization might be inappropriate for progressive kidney injury, especially among our patients receiving aggressive immunosuppressive treatment in active $\mathrm{LN}$.
Study limitations included a relatively short follow-up period of 6 months and no comparison of main renal outcomes to demonstrate the doubling of serum creatinine and initiating long-term dialysis. The relatively small sample size in our study limited the precision and power to detect associations of moderate strength. Differences in immunosuppressive agents used throughout the study could not be controlled, measurement of blood level of mycophenolate was not done and their influence on our data remains uncertain. Finally, follow-up was based on a serum creatinine level estimated GFR and urine protein for defining renal response, instead of renal biopsy, which may have mildly deviated renal outcomes.

\section{Conclusion}

In conclusion, this study indicates that NGAL in urine is one of biomarkers of the tubulointerstitial changes and perform better than conventional markers in predicting a clinical response to treatment of active LN. It may have the potential to predict renal response after induction therapy among SLE patients. Further investigation should focus on large populations with an analysis of urinary NGAL to find out whether NGAL can be used in clinical practice with higher sensitivity and specificity in predicting long term renal outcomes among SLE patients.

\begin{abstract}
Abbreviations
ALMS: Aspreva Lupus Management Study; ANA: Antinuclear antibodies; AUC: Area under the curve; Cl: Confidence interval; CKD-EPI: Chronic Kidney Disease Epidemiology Collaboration; ELISA: Enzyme-linked immunosorbent assay; GFR: Glomerular filtration rate; IQR: Interquartile range; LN: Lupus nephritis; NGAL: Neutrophil gelatinase-associated lipocalin; ROC: Receiver operating characteristic; SLE: Systemic lupus erythematosus; SLEDAl: SLE Disease Activity Index; UPCR: Urinary protein to urinary creatinine ratio
\end{abstract}

\section{Acknowledgements}

We gratefully acknowledge the contributions of the participating patients and general practitioners. We would like to thank Dollapas Punpanich, Research Unit, Department of Medicine, Phramongkutklao Hospital and College of Medicine for statistical analysis.

\section{Funding}

This study was supported by a grant from the National Science and Technology Development Agency (NSTDA, P-13-00505), and Ramathibodi Hospital, Bangkok, Thailand.

\section{Availability of data and materials \\ Data will not be shared regarding to our hospital's Human Research Ethics Committee regulation.}

\section{Authors' contributions}

$\mathrm{SB}, \mathrm{CK}, \mathrm{AL}, \mathrm{YA}$ and $\mathrm{OS}$ collected the data, drafted the article, reviewed the literature and revised it critically. BS provided valuable inputs in study design, data collection and literature review. BS and OS provided valuable inputs in data collection and literature review. CP provided literature review and revision of the draft. All authors read and approved the manuscript and met the criteria for authorship.

\section{Ethics approval and consent to participate}

The study was approved by the Ethics Committee of Institutional Review Board. Royal Thai Army Medical Department (IRB Number S004 h/57), Ramathibodi Hospital, Mahidol University, and Chulalongkorn Hospital, Chulaongkorn University, Bangkok, Thailand. All patients gave written informed consent. 


\section{Consent for publication}

Not applicable.

\section{Competing interests}

The authors declare that they have no competing interests.

\section{Publisher's Note}

Springer Nature remains neutral with regard to jurisdictional claims in published maps and institutional affiliations.

\section{Author details}

'Division of Nephrology, Department of Medicine, Phramongkutklao Hospital and College of Medicine, 315 Rachavitee Road, Phyathai, Bangkok 10400, Thailand. ${ }^{2}$ Division of Nephrology, Faculty of Medicine, Ramathibodi Hospital, Mahidol University, Bangkok, Thailand. ${ }^{3}$ Division of Nephrology, Department of Medicine, Faculty of Medicine, Chulalongkorn University, Bangkok, Thailand.

Received: 3 June 2017 Accepted: 28 July 2017

Published online: 04 August 2017

\section{References}

1. Samanta A, Feehally J, Roy S, Nichol FE, Sheldon PJ, Walls J. High prevalence of systemic disease and mortality in Asian subjects with systemic lupus erythematosus. Ann Rheum Dis. 1991;50(7):490-2.

2. Esdaile JM, Joseph L, MacKenzie T, Kashgarian M, Hayslett JP. The benefit of early treatment with immunosuppressive agents in lupus nephritis. J Rheumatol. 1994;21(11):2046-51.

3. Satirapoj B, Wongchinsri J, Youngprang N, Laonapaporn B, Chitrada T, Lapkittichareonchai S, Patumanon J. Predictors of renal involvement in patients with systemic lupus erythematosus. Asian Pac J Allergy Immunol. 2007;25(1):17-25.

4. Satirapoj B, Nast CC, Adler SG. Novel insights into the relationship between glomerular pathology and progressive kidney disease. Adv Chronic Kidney Dis. 2012;19(2):93-100.

5. Cowland JB, Borregaard N. Molecular characterization and pattern of tissue expression of the gene for neutrophil gelatinase-associated lipocalin from humans. Genomics. 1997:45(1):17-23.

6. Mishra J, Ma Q, Prada A, Mitsnefes M, Zahedi K, Yang J, Barasch J, Devarajan $P$. Identification of neutrophil gelatinase-associated lipocalin as a novel early urinary biomarker for ischemic renal injury. J Am Soc Nephrol. 2003;14(10): 2534-43.

7. Mishra J, Dent C, Tarabishi R, Mitsnefes MM, Ma Q, Kelly C, Ruff SM, Zahedi K, Shao M, Bean J, et al. Neutrophil gelatinase-associated lipocalin (NGAL) as a biomarker for acute renal injury after cardiac surgery. Lancet. 2005; 365(9466):1231-8

8. Mishra J, Mori K, Ma Q, Kelly C, Barasch J, Devarajan P. Neutrophil gelatinase-associated lipocalin: a novel early urinary biomarker for cisplatin nephrotoxicity. Am J Nephrol. 2004;24(3):307-15.

9. Woo KS, Choi JL, Kim BR, Kim JE, An WS, Han JY. Urinary neutrophil gelatinase-associated lipocalin levels in comparison with glomerular filtration rate for evaluation of renal function in patients with diabetic chronic kidney disease. Diabetes Metab J. 2012;36(4):307-13.

10. Sirisopha A, Vanavanan S, Chittamma A, Phakdeekitcharoen B, Thakkinstian A, Lertrit A, Sathirapongsasuti N, Kitiyakara C. Effects of Therapy on Urine Neutrophil Gelatinase-Associated Lipocalin in Nondiabetic Glomerular Diseases with Proteinuria. Int J Nephrol. 2016;2016:4904502.

11. Brunner HI, Mueller M, Rutherford C, Passo MH, Witte D, Grom A, Mishra J, Devarajan P. Urinary neutrophil gelatinase-associated lipocalin as a biomarker of nephritis in childhood-onset systemic lupus erythematosus. Arthritis Rheum. 2006;54(8):2577-84.

12. Satirapoj B, Jirawatsiwaporn K, Tangwonglert T, Choovichian P. Performance of the estimated glomerular filtration rate creatinine and cystatin $C$ based equations in Thai patients with chronic glomerulonephritis. Int J Nephrol Renovasc Dis. 2015;8:145-50.

13. Bombardier C, Gladman DD, Urowitz MB, Caron D, Chang CH. Derivation of the SLEDAI. A disease activity index for lupus patients. The Committee on Prognosis Studies in SLE. Arthritis Rheum. 1992;35(6):630-40.

14. Austin HA III, Muenz LR, Joyce KM, Antonovych TT, Balow JE. Diffuse proliferative lupus nephritis: Identification of specific pathologic features affecting renal outcome. Kidney Int. 1984;25(4):689-95.
15. Eddy AA, Neilson EG. Chronic kidney disease progression. J Am Soc Nephrol. 2006;17(11):2964-6.

16. Bolignano D, Donato V, Coppolino G, Campo S, Buemi A, Lacquaniti A, Buemi M. Neutrophil gelatinase-associated lipocalin (NGAL) as a marker of kidney damage. Am J Kidney Dis. 2008;52(3):595-605.

17. Pawar RD, Pitashny M, Gindea S, Tieng AT, Levine B, Goilav B, Campbell SR, Xia Y, Qing X, Thomas DB, et al. Neutrophil gelatinase-associated lipocalin is instrumental in the pathogenesis of antibody-mediated nephritis in mice. Arthritis Rheum. 2012;64(5):1620-31.

18. Pawar RD, Goilav B, Xia Y, Zhuang H, Herlitz L, Reeves WH, Putterman C. Serum autoantibodies in pristane induced lupus are regulated by neutrophil gelatinase associated lipocalin. Clin Immunol. 2014;154(1):49-65.

19. Sharifipour F, Zeraati A, Sahebari M, Hatef M, Naghibi M, Rezaieyazdi Z, Mahmoudi M, Azarian AA, Mirfeizi Z, Samadi K. Association of urinary lipocalin-2 with lupus nephritis. Iran J Basic Med Sci. 2013;16(9):1011-5.

20. Rubinstein T, Pitashny M, Levine B, Schwartz N, Schwartzman J, Weinstein E, Pego-Reigosa JM, Lu TY, Isenberg D, Rahman A, et al. Urinary neutrophil gelatinase-associated lipocalin as a novel biomarker for disease activity in lupus nephritis. Rheumatology (Oxford). 2010;49(5):960-71.

21. Fang YG, Chen NN, Cheng YB, Sun SJ, Li HX, Sun F, Xiang Y. Urinary neutrophil gelatinase-associated lipocalin for diagnosis and estimating activity in lupus nephritis: a meta-analysis. Lupus. 2015;24(14):1529-39.

22. Kuwabara T, Mori K, Mukoyama M, Kasahara M, Yokoi H, Saito Y, Yoshioka T, Ogawa Y, Imamaki H, Kusakabe T, et al. Urinary neutrophil gelatinaseassociated lipocalin levels reflect damage to glomeruli, proximal tubules, and distal nephrons. Kidney Int. 2009;75(3):285-94.

23. Elewa EA, El Tokhy MA, Fathy SE, Talaat AM. Predictive role of urinary neutrophil gelatinase-associated lipocalin in lupus nephritis. Lupus. 2015;24(2):138-46.

24. Lin HY, Lee SC, Lin SF, Hsiao HH, Liu YC, Yang WC, Hwang DY, Hung CC, Chen HC, Guh JY. Urinary neutrophil gelatinase-associated lipocalin levels predict cisplatin-induced acute kidney injury better than albuminuria or urinary cystatin C levels. Kaohsiung J Med Sci. 2013;29(6):304-11.

25. Alharazy SM, Kong NC, Mohd M, Shah SA, Abdul Gafor AH, Ba'in A. The role of urinary neutrophil gelatinase-associated lipocalin in lupus nephritis. Clin Chim Acta. 2013;425:163-8.

26. Pitashny M, Schwartz N, Qing X, Hojaili B, Aranow C, Mackay M, Putterman C. Urinary lipocalin-2 is associated with renal disease activity in human lupus nephritis. Arthritis Rheum. 2007;56(6):1894-903.

27. Yang CC, Hsieh SC, Li KJ, Wu CH, Lu MC, Tsai CY, Yu CL. Urinary neutrophil gelatinase-associated lipocalin is a potential biomarker for renal damage in patients with systemic lupus erythematosus. J Biomed Biotechnol. 2012;2012:759313.

28. Amezcua-Guerra LM, Springall $R$, Arrieta-Alvarado AA, Rodriguez V, RiveraMartinez E, Castillo-Martinez D, Bojalil R. C-reactive protein and complement components but not other acute-phase reactants discriminate between clinical subsets and organ damage in systemic lupus erythematosus. Clin Lab. 2011;57(7-8):607-13.

29. Al Durahim H, Al Ghamdi G, Al Seraya A, Alkhiari R, Al Sayyari A. Predictors of mortality and end stage renal disease in Saudi patients with lupus nephritis. Lupus. 2011;20(12):1329-35.

30. Dall'Era M, Stone D, Levesque V, Cisternas M, Wofsy D. Identification of biomarkers that predict response to treatment of lupus nephritis with mycophenolate mofetil or pulse cyclophosphamide. Arthritis Care Res (Hoboken). 2011;63(3):351-7.

31. Li Y, Tucci M, Narain S, Barnes EV, Sobel ES, Segal MS, Richards HB. Urinary biomarkers in lupus nephritis. Autoimmun Rev. 2006;5(6):383-8.

32. Tang KW, Toh QC, Teo BW. Normalisation of urinary biomarkers to creatinine for clinical practice and research-when and why. Singap Med J. 2015;56(1):7-10.

33. Waikar SS, Sabbisetti VS, Bonventre JV. Normalization of urinary biomarkers to creatinine during changes in glomerular filtration rate. Kidney Int. 2010; 78(5):486-94. 